\title{
Determinants of a healthy lifestyle and use of preventive screening in Canada Vikky Qi ${ }^{1}$, Susan P Phillips ${ }^{1}$ and Wilma M Hopman*2
}

\begin{abstract}
Address: ${ }^{1}$ Department of Family Medicine, Queen's University, Kingston, Ontario, Canada and ${ }^{2}$ Clinical Research Centre, Kingston General Hospital; Department of Community Health and Epidemiology, Queen's University, Kingston, Ontario, Canada

Email: Vikky Qi - vikkyqi@hotmail.com; Susan P Phillips - phillip@post.queensu.ca; Wilma M Hopman* - hopmanw@post.queensu.ca

* Corresponding author
\end{abstract}

Published: 07 November 2006

BMC Public Health 2006, 6:275 doi:10.1 I86/147|-2458-6-275
Received: 08 June 2006

Accepted: 07 November 2006

This article is available from: http://www.biomedcentral.com//47/-2458/6/275

(C) 2006 Qi et al; licensee BioMed Central Ltd.

This is an Open Access article distributed under the terms of the Creative Commons Attribution License (http://creativecommons.org/licenses/by/2.0), which permits unrestricted use, distribution, and reproduction in any medium, provided the original work is properly cited.

\begin{abstract}
Background: This study explores the associations between individual characteristics such as income and education with health behaviours and utilization of preventive screening.

Methods: Data from the Canadian National Population Health Survey (NPHS) 1998-9 were used. Independent variables were income, education, age, sex, marital status, body mass index, urban/ rural residence and access to a regular physician. Dependent variables included smoking, excessive alcohol use, physical activity, blood pressure checks, mammography in past year and Pap smear in past 3 years. Logistic regression models were developed for each dependent variable.

Results: 13,756 persons 20 years of age and older completed the health portion of the NPHS. In general, higher levels of income were associated with healthier behaviours, as were higher levels of education, although there were exceptions to both. The results for age and gender also varied depending on the outcome. The presence of a regular medical doctor was associated with increased rates of all preventive screening and reduced rates of smoking.

Conclusion: These results expand upon previous data suggesting that socioeconomic disparities in healthy behaviours and health promotion continue to exist despite equal access to medical screening within the Canadian healthcare context. Knowledge, resources and the presence of a regular medical doctor are important factors associated with identified differences.
\end{abstract}

\section{Background}

A socioeconomic gradient favouring those with greater income exists for a variety of chronic conditions, including cardiovascular disease, most cancers, diabetes, hypertension, arthritis, respiratory disease, gastrointestinal disease and metabolic syndrome [1]. Many of these can be prevented, identified early, or ameliorated by screening and individual behaviour.
Major behavioral factors affecting health include nutrition, physical activity, tobacco use, and excessive alcohol consumption. Low socioeconomic status has been associated with a more sedentary lifestyle and lower fruit and vegetable consumption [2]. A study based on the 1990 Canadian Health Promotion Survey found significant associations between socioeconomic class and patterns of exercise [3]. Although patterns of alcohol consumption are more complex, low socioeconomic status is linked to 
heavy drinking $[2,4]$, and tobacco smoking follows the same trend $[2,3,5-7]$.

Screenings such as mammography, Papanicolaou (Pap) smear testing and blood pressure (BP) measurement reduce mortality [8-10]. Studies in the US show that greater wealth is associated with higher utilization of these screening tests [11-15], even after controlling for insurance status, health status and usual source of care [16]. Likewise, a study comparing socioeconomic disparities in breast and cervical cancer screening in Ontario and the US found that the association between income and screening was similar in both populations, suggesting that factors unrelated to medical insurance coverage and access to care play a significant role [11].

Lifestyle factors and screening are components of health promotion and prevention. The Canadian Task Force on Preventive Health Care recommends that physicians counsel patients on nutritional habits, physical activity, smoking cessation and alcohol abuse, and offer blood pressure checks for all adults, Pap smears every 1-3 years for women from first sexual activity to age 69, and mammograms every 1-2 years for women aged 50-69 [6].

Previous studies in Canada have been based on earlier data, were focused on specific behaviors and maneuvers, or were limited to specific areas of the country [11-13]. The purpose of this study is to gain a more current view of the association between socioeconomic status, as indicated by income and education, and health promotion, lifestyle factors and use of screening, using data from a representative population-based health survey.

\section{Methods}

Data from the Health File of the 1998-9 National Population Health Survey (NPHS) household component were used. The survey included questions relating to sociodemographic information, such as age, sex, education, household income and ethnicity, as well as health status, determinants of health and use of health services. The household component of the NPHS sampled household residents of all provinces in Canada, excluding Indian reserves, Canadian Forces Bases and some remote areas. Within each household, information was collected from each member (general file) and one person was randomly selected to complete a more in-depth interview and a longitudinal follow-up (health file) [16]. In addition, a crosssectional sample was selected to compensate for sample attrition since 1994-5, and to account for populations not represented by the initial sample and those who were born or immigrated after 1994 .

The survey was conducted by computer assisted interviewing (CAI), which allowed interviews to be customized to each respondent. Interviewers were trained specifically on the use of CAI for this survey. Most interviews were conducted by telephone. Personal visits were made if respondents did not have telephone access or at the respondent's request. On average, the interview's duration was one hour per household.

Weights were computed using an approach where an initial weight representing the inverse probability of selection was computed, then adjusted to take into account the various specifics of the survey. The typical adjustment was to compensate for non-response; homogeneous response groups were formed based on data available from both respondents and non-respondents [16]. A detailed description of the randomized study selection, calculation of weights and data collection is available elsewhere (NPHS User Guide) [16]. Survey design variables such as the primary sampling unit were not included in the analysis, as these are incorporated into the sampling weights.

The principal independent variables of interest were total annual household income and highest level of education. Income groups were collapsed to form 5 categories: < $\$ 20,000$, \$20,000-39,999, \$40,000-59,999, \$60,00079,999 , and $=\$ 80,000$ (all in Canadian dollars). Education was categorized as less than secondary school, secondary school graduate, other postsecondary (e.g. trade, technical or vocational school), and college or university. Other independent variables were age (represented in 5year increments), sex $(1=$ male, $2=$ female $)$, marital status ( 1 = with a partner, $2=$ no partner), body mass index (BMI, defined as weight in kilograms divided by height in meters squared) and residence ( $1=$ rural, $2=$ urban, where urban areas are defined as continuously built-up areas having a population concentration of 1,000 or more and a population density of 400 or more per square kilometer). In addition, participant responses to the question "Do you have a regular family doctor?" were also included as an independent variable $(1=$ yes, $2=$ no $)$. These covariates were included based on previous studies showing their relationship to health promotion and preventive services [17-21].

All dependent variables were dichotomous and included Pap smear within the past 3 years, mammogram within the past year, BP taken within the past year, smoking status (no versus daily/occasionally) and alcohol consumption $=12$ drinks per week. Physical activity was based on responses to a number of questions, including 21 specific activities and the frequency with which the respondent engaged in these activities. These responses were used to develop an overall frequency indicator of "regular", "occasional" and "infrequent", which were collapsed into the dichotomous variable of "regular" versus "occasional/ infrequent". All variables were categorized according the 
Canadian Task Force on Preventive Health Care recommendations [10]. For the Pap smear, analysis was conducted on the subgroup of women aged 20-69 years, and for mammography, the subgroup of women aged 50-69 years. The study was limited to adults aged 20 years and over, as a number of the variables did not apply to those under 20 years. Ethics review was not required for this study.

\section{Statistical analysis}

Crude frequencies and adjusted frequencies based on the population weights were calculated. Independent associations of education and total household income with each dependent variable, adjusting for age, sex, marital status, body mass index (BMI), regular medical doctor, and rural versus urban residence, were assessed by logistic regression, with all variables entered simultaneously. Income and education were categorical variables, so separate estimates are presented for each level. However, age, beginning with 20 to 24 years and ending at $80+$ years, was treated as continuous despite being ordinal in nature, as there were 13 levels. Separate regressions were carried out for each health prevention measure, and reported results include the odds ratio (OR) and the associated 95\% confidence interval (CI). Missing values and those considered "not applicable" were excluded from the analysis, with the exception of income level, where this was added as a separate category as this represented $6 \%$ of the sample. Appropriate sampling weights were applied in accordance with the design of the NPHS [16]. All analyses were performed using SPSS [Version 12.0.1, SPSS Incorporated, Chicago, Illinois, 2003].

\section{Results}

A total of 13,756 adults aged 20 years and over completed the health portion of the NPHS 1998-9 cycle. The response rate for the health portion was $82.6 \%$ overall, calculated as the number of health surveys completed/ total number of selected households. Table 1 contains the raw and weighted values of the sample characteristics. Table 2 contains the frequencies and the weighted and unweighted percentages for each of the outcomes. Tables 3 and 4 provide the complete logistic regression model for each health behaviour, including the odds ratio and the $95 \%$ confidence intervals, as well as the significance level of each variable. The Cox \& Snell $\mathrm{r}^{2}$ provides an estimate of the percentage of variation in outcome accounted for by the model, while the Hosmer \& Lemeshow $\mathrm{X}^{2}$ provides an estimate of model fit (a significant p-value suggests that the model does not adequately fit the data).

\section{Blood pressure check}

Lower $(<\$ 40,000)$ levels of income were associated with blood pressure checks, while the middle and higher ranges of income were not. Those whose level of income was not reported also had higher rates of blood pressure checks. On the other hand, those with lower education were less likely to have blood pressure checks. Other factors associated with a greater likelihood of having regular checks included older age, being female, urban residence, having a regular medical doctor, and higher BMI. Marital status was not significantly associated with blood pressure checks. The model accounted for $6.9 \%$ of the variation in outcome, although the goodness of fit tests suggests that the model does not adequately fit the data $(\mathrm{p}=0.02)$.

\section{Mammography}

In women aged 50-69, mammography within the past year was associated with income only for those in the mid- to high-income category, that is, between $\$ 60,000$ and \$79,000 annually. Education was not strongly associated with mammography. Other factors associated with higher rates of mammography included older age, having a regular medical doctor, and higher BMI. There was a trend toward a direct association between having a partner and mammography screening. Rural or urban residence was not significantly associated with mammography. The model accounted for $5.6 \%$ of the variation in outcome, and is a reasonable fit for the data $(\mathrm{p}=$ $0.13)$.

\section{Papanicolaou test}

In women aged 20 to 69 years, there is a clear trend towards increased utilization of Pap testing as income increases, although the highest probability of being tested was in those whose income was not reported. Lower education was associated with lower use of Pap testing. Other covariates associated with a Pap test in the past 3 years included younger age and having a regular medical doctor. Marital status, rural or urban residence and BMI were not strongly associated with Pap testing. The model accounted for $7.9 \%$ of the variation in outcome, and is a reasonable fit for the data $(\mathrm{p}=0.23)$.

\section{Smoking}

Lower levels of income were associated with a greater likelihood of smoking. The lowest odds ratio for smoking was in those whose income was not reported. As education level increased, the odds of smoking decreased. Other covariates associated with smoking included lower age, marital status (no partner), no regular medical doctor, and lower BMI. There was a strong trend towards more smoking among men $(\mathrm{p}=0.075)$. Rural versus urban residence was not significantly associated with smoking. The model accounted for $5.6 \%$ of the variation in outcome, and is a reasonable fit for the data $(\mathrm{p}=0.13)$.

\section{Alcohol}

Excessive alcohol consumption was more prevalent amongst those with lower incomes, but the association 
Table I: Sample Characteristics and Frequencies $(n=13,756)$

\begin{tabular}{|c|c|c|c|}
\hline Variable & Number & Percent & Weighted percent \\
\hline \multicolumn{4}{|l|}{ Total Household Income } \\
\hline$<\$ 20,000$ & 2879 & 20.9 & 15.6 \\
\hline$\$ 20,000-39,999$ & 3805 & 27.7 & 25.1 \\
\hline$\$ 40,000-59,999$ & 2776 & 20.2 & 21.6 \\
\hline$\$ 60,000-79,999$ & 1712 & 12.4 & 14.7 \\
\hline$>=\$ 80,000$ & 1762 & 12.8 & 16.5 \\
\hline Missing & 822 & 6.0 & 6.5 \\
\hline \multicolumn{4}{|l|}{ Education Level } \\
\hline$<$ Secondary School & 3505 & 25.5 & 22.5 \\
\hline Secondary School Graduate & 2005 & 14.6 & 15.4 \\
\hline Other Post-Secondary & 3575 & 26.0 & 26.7 \\
\hline College/University Degree & 4659 & 33.9 & 35.3 \\
\hline \multicolumn{4}{|l|}{ Age Group* } \\
\hline $20-39$ years & 5328 & 38.8 & 40.8 \\
\hline $40-59$ years & 4740 & 34.5 & 37.0 \\
\hline $60-79$ years & 3021 & 22.0 & 19.1 \\
\hline$>=80$ years & 667 & 4.8 & 3.2 \\
\hline \multicolumn{4}{|l|}{ Sex } \\
\hline Male & 6248 & 45.4 & 48.8 \\
\hline Female & 7508 & 54.6 & 51.2 \\
\hline \multicolumn{4}{|l|}{ Marital Status } \\
\hline With a partner & 8198 & 59.6 & 65.2 \\
\hline Without a partner & 5558 & 40.4 & 34.8 \\
\hline \multicolumn{4}{|l|}{ Rural Versus Urban Residence } \\
\hline Rural & 3058 & 22.2 & 16.7 \\
\hline Urban & 10697 & 77.8 & 83.3 \\
\hline \multicolumn{4}{|l|}{ Regular Medical Doctor } \\
\hline Yes & 11956 & 86.9 & 86.5 \\
\hline No & 1799 & 13.1 & 13.5 \\
\hline Body Mass Index (mean \pm standard deviation) & 10683 & $25.8 \pm 4.6$ & $25.6 \pm 4.5$ \\
\hline
\end{tabular}

12 were missing education level; I was missing information about regular doctor

* In the analyses, age was categorized in 5-year increments, e.g. 20-24, 25-29, etc.

was only significant for the income level of $\$ 20,000$ $\$ 39,000$. Education level showed the same pattern, with higher odds of excessive drinking at lower education levels. Other factors associated with excessive drinking included older age, being male, and higher BMI. Marital status, rural versus urban residence and having a regular medical doctor were not strongly associated with alcohol consumption. The model only accounted for $2.6 \%$ of the variation in outcome, although the model was a reasonable fit for the data $\mathrm{p}=0.25$ ).

\section{Regular physical activity}

Respondents with higher incomes were more likely to engage in regular physical activity. This association attained statistical significance in those with an income of greater than $\$ 80,000$ annually. The group that did not report their income also had higher odds of being involved in regular physical activity. Lower education was associated with a lower likelihood of being involved in regular physical activity. Other factors associated with regular physical activity included being female, having no partner, urban residence and lower BMI. Age and presence of a regular medical doctor were not significantly associated with regular physical activity. The model was not strong, accounting for only $2.3 \%$ of the variation, but it was a very good fit for the data $(\mathrm{p}=0.94)$.

\section{Discussion}

Our results are compatible with previous studies, both in Canada and other countries. Several studies in Canada 
Table 2: Preventive Health Characteristics and Frequencies

\begin{tabular}{lccc}
\hline Preventive Health Measure & Total & Percent & Weighted Percent \\
\hline Blood pressure check in past year & 10298 & 77.7 & 76.6 \\
Mammogram in past year in women aged $50-69$ & 869 & 54.7 & 55.3 \\
Pap Smear in past 3 years in women aged 20-69 & 4918 & 85.1 & 81.8 \\
Regular smoker & 4252 & 30.9 & 27.7 \\
Regularly drinks > 12 units of alcohol per week & 368 & 2.7 & 2.0 \\
Frequent physical activity & 8104 & 58.9 & 61.1 \\
\hline
\end{tabular}

have linked mammography and Pap smear rates to socioeconomic status [11-13,22,23]. Another study in Canada linked socioeconomic status to patterns of exercise [3]. Lower income and education have been associated with smoking, alcohol consumption and blood pressure monitoring in U.S. and European studies [4,6,7].

Those with a higher household income were more likely to have had a Pap smear in the preceding three years, a mammogram in the previous year, to have lower levels of alcohol consumption, to be non-smokers, and to be physically active. However, those with lower incomes were more likely to have had their blood pressure checked in the previous 12 months, which may be explained by two factors. First, lower income Canadians use primary health care more frequently than their wealthier counterparts [2], affording more opportunities for physicians to check blood pressure. Secondly, lower income is associated with higher rates of hypertension, diabetes, heart disease and cerebral vascular disease [1], so blood pressure may have been monitored as a part of disease management rather than as a preventive screening.

Increased income was also associated with decreased alcohol consumption. Although previous studies have shown conflicting results, moderate drinking appears to be more common at higher socioeconomic levels, and heavy drinking more common at lower socioeconomic levels $[4,5]$, findings supported by our results.

Higher educational level was associated with a BP check in the past year, not smoking, not drinking excessively and increased physical activity. Women with less education were also less likely to have had a Pap smear in the previous three years. There was no strong association between education and mammography.

Prerequisites for regular physical activity include facilities, motivation and time. Those with a lower income and education may have limited means to pursue healthy preventive behaviours, as poorer neighborhoods often lack good recreational facilities and those with a lower income are less able to afford memberships or equipment for physical activity.
Access to a regular medical doctor was significantly associated with a reduced rate of smoking, as were higher income and higher education. One study showed that rates of smoking initiation are similar regardless of education, but quitting rates are dramatically higher in the educated [2]. The impact of access to medical care can also be seen in the higher rates of screening and use of preventive health services among those with a regular family physician, as well as the lower rate of smoking mentioned above. In Canada, the number of physicians per 1,000 population has decreased from 1.91 in 1995 to 1.85 in 1999. Projections based on current supply levels suggest this ratio will decrease to $1.4 / 1000$ in 2021 [24]. With $13.5 \%$ of respondents indicating that they had no regular family physician, this can have a serious detrimental effect on the health of Canadians, and the use of preventive heath screening and services.

Limitations of this study should be discussed. The NPHS data were based exclusively on self-reporting. Thus, some of the measures of preventive health may have been overor underestimated. In addition, the large sample size, while being a strength of the NPHS, also means that small differences can attain statistical significance. For this reason, the OR and the 95\% CI were provided, to allow the application of clinical judgment when interpreting the results. The study excludes certain groups, such as Aboriginals, military personnel and those who spoke neither English nor French. Because of the nature and length of the interview, the results may be skewed towards those who had time to respond to the questions. As the data are cross-sectional in nature, associations can be identified but direction and causality cannot be inferred. Finally, it would be of interest to examine these associations within men and women separately, in future work.

\section{Conclusion}

Lower socioeconomic status has consistently been linked to chronic disease and mortality, while certain lifestyle factors and preventive health strategies improve health. This study explored the associations of income and education with lifestyle factors such as smoking, alcohol use and exercise, as well as with utilization of preventive screening. The findings support and expand on those of 
Table 3: Logistic Regression Models for Blood Pressure, Mammogram and Pap Test

\begin{tabular}{|c|c|c|}
\hline $\begin{array}{l}\text { Blood Pressure Check in Past Year, } N=10,320 \\
\text { Cox \& Snell } r^{2}=0.069 \\
\text { Hosmer \& Lemeshow } X^{2}=18.3, p=0.02\end{array}$ & Odds Ratio (95\% Cl) & p-value \\
\hline \multicolumn{3}{|l|}{ Total household income (reference $=<\$ 19,999$ ) } \\
\hline$\$ 20-39,999$ & $1.42(1.12,1.79)$ & 0.003 \\
\hline$\$ 40-59,999$ & $1.14(0.92,1.41)$ & 0.245 \\
\hline$\$ 60-79,999$ & I.II $(0.89,1.38)$ & 0.374 \\
\hline$\$ 80,000+$ & $1.14(0.90,1.44)$ & 0.267 \\
\hline Missing & $1.33(1.06,1.68)$ & 0.016 \\
\hline \multicolumn{3}{|l|}{ Education level (reference < secondary school) } \\
\hline Secondary school graduate & $0.83(0.72,0.95)$ & 0.008 \\
\hline Other post-secondary & $0.83(0.72,0.96)$ & 0.009 \\
\hline College/University degree(s) & $1.00(0.89,1.13)$ & 0.961 \\
\hline Age (5-year increments) & $1.12(1.09,1.14)$ & $<0.001$ \\
\hline $\operatorname{Sex}(I=$ male, $2=$ female $)$ & $1.86(1.69,2.04)$ & $<0.001$ \\
\hline Marital status $(I=$ with partner, 2 = no partner $)$ & $0.97(0.88,1.08)$ & 0.621 \\
\hline Rural/Urban $(I=$ rural, $2=$ urban $)$ & $1.14(1.02,1.27)$ & 0.024 \\
\hline Regular medical doctor $(I=$ yes, $2=$ no $)$ & $0.40(0.36,0.45)$ & $<0.001$ \\
\hline Body mass index (numeric) & $1.05(1.04,1.06)$ & $<0.001$ \\
\hline $\begin{array}{l}\text { Mammogram in Past Year, Women 50-69, N = I, } 192 \\
\text { Cox \& Snell } r^{2}=0.056 \\
\text { Hosmer \& Lemeshow } X^{2}=12.6, p=0.13\end{array}$ & Odds Ratio (95\% Cl) & p-value \\
\hline \multicolumn{3}{|l|}{ Total household income (reference $=<\$ 19,999$ ) } \\
\hline$\$ 20-39,999$ & I.0I $(0.58,1.76)$ & 0.963 \\
\hline$\$ 40-59,999$ & $1.28(0.77,2.13)$ & 0.343 \\
\hline$\$ 60-79,999$ & $1.90(1.11,3.25)$ & 0.019 \\
\hline$\$ 80,000+$ & $1.15(0.63,2.08)$ & 0.652 \\
\hline Missing & $1.59(0.89,2.83)$ & 0.114 \\
\hline \multicolumn{3}{|l|}{ Education level (reference < secondary school) } \\
\hline Secondary school graduate & $0.85(0.62,1.18)$ & 0.339 \\
\hline Other post-secondary & $1.03(0.7 \mathrm{I}, \mathrm{I} .5 \mathrm{I})$ & 0.865 \\
\hline College/University degree(s) & $0.89(0.65,1.22)$ & 0.480 \\
\hline Age (5-year increments) & $1.16(1.00,1.34)$ & 0.047 \\
\hline Marital status ( $($ = with partner, 2 = no partner $)$ & $0.80(0.60,1.05)$ & 0.106 \\
\hline Rural/Urban $(I=$ rural, $2=$ urban $)$ & $1.14(0.85,1.520$ & 0.377 \\
\hline Regular medical doctor $(I=$ yes, $2=$ no $)$ & $0.53(0.29,0.97)$ & 0.040 \\
\hline Body mass index (numeric) & $1.02(1.00,1.05)$ & 0.059 \\
\hline $\begin{array}{l}\text { Pap Test in Past } 3 \text { Years, Women } 20-69, N=5,192 \\
\text { Cox \& Snell } r^{2}=0.079 \\
\text { Hosmer \& Lemeshow } X^{2}=10.5, p=0.23\end{array}$ & Odds Ratio (95\% Cl) & p-value \\
\hline \multicolumn{3}{|l|}{ Total household income $($ reference $=<\$ 19,999)$} \\
\hline$\$ 20-39,999$ & $0.85(0.57,1.25)$ & 0.406 \\
\hline$\$ 40-59,999$ & $1.15(0.80,1.68)$ & 0.450 \\
\hline$\$ 60-79,999$ & $1.27(0.86,1.86)$ & 0.226 \\
\hline$\$ 80,000+$ & $1.59(1.04,2.42)$ & 0.033 \\
\hline Missing & $2.28(1.47,3.56)$ & $<0.001$ \\
\hline \multicolumn{3}{|l|}{ Education level (reference < secondary school) } \\
\hline Secondary school graduate & $0.73(0.58,0.93)$ & 0.011 \\
\hline Other post-secondary & I.II $(0.84,1.46)$ & 0.458 \\
\hline College/University degree(s) & $0.93(0.75,1.15)$ & 0.501 \\
\hline Age (5-year increments) & $0.76(0.73,0.79)$ & $<0.001$ \\
\hline Marital status $(I=$ with partner, 2 = no partner $)$ & $1.06(0.87,1.30)$ & 0.545 \\
\hline Rural/Urban $(I=$ rural, $2=$ urban $)$ & $1.09(0.89,1.32$ & 0.425 \\
\hline Regular medical doctor $(I=$ yes, $2=$ no $)$ & $0.36(0.28,0.46)$ & $<0.001$ \\
\hline Body mass index (numeric) & $0.99(0.97,1.00)$ & 0.142 \\
\hline
\end{tabular}

$\mathrm{Cl}=$ Confidence Interval

previous research. Factors contributing to identified dif- 
Table 4: Logistic Regression Models for Regular Smoking, Alcohol Consumption and Physical Activity

\begin{tabular}{|c|c|c|}
\hline $\begin{array}{l}\text { Regular Smoker, } N=10,664 \\
\text { Cox \& Snell } r^{2}=0.056 \\
\text { Hosmer \& Lemeshow } X^{2}=12.6, p=0.13\end{array}$ & Odds Ratio $(95 \% \mathrm{Cl})$ & p-value \\
\hline \multicolumn{3}{|l|}{ Total household income (reference $=<\$ 19,999$ ) } \\
\hline$\$ 20-39,999$ & $1.40(1.14,1.72)$ & 0.002 \\
\hline$\$ 40-59,999$ & $1.32(1.09,1.61)$ & 0.005 \\
\hline$\$ 60-79,999$ & $1.07(0.88,1.31)$ & 0.496 \\
\hline$\$ 80,000+$ & $0.96(0.77,1.18)$ & 0.682 \\
\hline Missing & $0.62(0.50,0.77)$ & $<0.001$ \\
\hline \multicolumn{3}{|l|}{ Education level (reference < secondary school) } \\
\hline Secondary school graduate & $2.59(2.29,2.92)$ & $<0.001$ \\
\hline Other post-secondary & $1.71(1.51,1.94)$ & $<0.001$ \\
\hline College/University degree(s) & $1.45(1.31,1.61)$ & $<0.001$ \\
\hline Age (5-year increments) & $0.97(0.95,0.98)$ & $<0.001$ \\
\hline $\operatorname{Sex}(I=$ male, $2=$ female $)$ & $0.93(0.85,1.01)$ & 0.075 \\
\hline Marital status ( $I$ = with partner, 2 = no partner $)$ & $1.16(1.06,1.28)$ & 0.001 \\
\hline Rural/Urban $(I=$ rural, $2=$ urban $)$ & $0.93(0.84,1.02)$ & 0.130 \\
\hline Regular medical doctor $(I=$ yes, $2=$ no $)$ & $1.25(1.12,1.40)$ & $<0.001$ \\
\hline Body mass index (numeric) & $0.98(0.97,0.99)$ & $<0.001$ \\
\hline $\begin{array}{l}\text { Alcohol Consumption }>I 2 / w k, N=10,677 \\
\text { Cox \& Snell } r^{2}=0.026 \\
\text { Hosmer \& Lemeshow } X^{2}=10.3, p=0.25\end{array}$ & Odds Ratio (95\% Cl) & p-value \\
\hline
\end{tabular}

Total household income (reference $=<\$ 19,999)$ $\$ 20-39,999$

$\$ 40-59,999$

$2.98(1.46,6.04)$

0.003

$\$ 60-79,999$

$1.87(0.93,3.76)$

0.081

$1.27(0.61,2.62)$

0.520

$\$ 80,000+$

$1.15(0.53,2.47)$

0.723

Missing

$1.30(0.61,2.79)$

0.498

Education level (reference < secondary school)

Secondary school graduate

Other post-secondary

College/University degree(s)

$2.08(1.47,2.93)$

$<0.001$

$1.15(0.74,1.79)$

0.527

$1.74(1.24,2.43)$

0.001

Age (5-year increments)

Sex $(I=$ male, $2=$ female $)$

$1.23(1.16,1.30)$

$<0.001$

$0.22(0.16,0.29)$

$<0.001$

Marital status ( $I=$ with partner, $2=$ no partner $)$

$1.10(0.83,1.45)$

0.508

$0.95(0.72,1.25)$

0.692

Regular medical doctor $(I=$ yes, $2=$ no)

$0.81(0.56,1.16)$

0.245

Body mass index (numeric)

$1.03(1.00,1.06)$

0.033

Regular Physical Activity, N = 10,537

Cox \& Snell $r^{2}=0.023$

Odds Ratio (95\% Cl)

p-value

Hosmer \& Lemeshow $X^{2}=2.8, p=0.94$

Total household income (reference $=<\$ 19,999$ )

$\$ 20-39,999$

$\$ 40-59,999$

$\$ 60-79,999$

$\$ 80,000+$

Missing

Education level (reference < secondary school)

Secondary school graduate

Other post-secondary

College/University degree(s)

Age (5-year increments)

Sex $(I=$ male, $2=$ female $)$

Marital status $(I=$ with partner, $2=$ no partner $)$

Rural/Urban ( 1 = rural, 2 = urban)

Regular medical doctor $(I=$ yes, $2=$ no)

Body mass index (numeric)

$\begin{array}{lc}0.86(0.70,1.05) & 0.145 \\ 0.98(0.81,1.18) & 0.806 \\ 1.08(0.89,1.31) & 0.446 \\ 1.33(1.08,1.62) & 0.007 \\ 1.65(1.34,2.04) & <0.001 \\ & \\ 0.69(0.62,0.78) & <0.001 \\ 0.81(0.71,0.91) & <0.001 \\ 0.90(0.81,0.99) & 0.001 \\ 0.99(0.97,1.01) & 0.104 \\ 1.09(1.01,1.18) & 0.038 \\ 1.17(1.07,1.28) & 0.001 \\ 1.10(1.00,1.21) & 0.047 \\ 0.92(0.82,1.03) & 0.141 \\ 0.98(0.97,0.99) & <0.001\end{array}$

$\mathrm{Cl}=$ Confidence Interval 
ferences include knowledge, resources and availability of physicians. Despite equal access to medical screening and intervention within the Canadian health care context, socio-economic disparities persist. Targeted interventions would likely contribute to reducing these disparities in the health of Canadians.

\section{Competing interests}

The author(s) declare that they have no competing interests.

\section{Authors' contributions}

VQ and SPP participated in the conception and design of the study; VQ and WMH were involved in the analysis; $\mathrm{VQ}$, SPP and WMH were involved in the interpretation of the findings and the drafting of the manuscript; all have read and approved the final manuscript.

\section{Acknowledgements}

This research was unfunded.

\section{References}

I. Adler NE, Ostrove JM: Socioeconomic status and health: what we know and what we don't. Annals of the New York Academy of Sciences 1999, 896:3-15.

2. Adler NE, Newman K: Socioeconomic disparities in health: pathways and policies. Health Affairs 2002, 21 :60-76.

3. Wister AV: The effects of socioeconomic status on exercise and smoking: age-related differences. Journal of Aging \& Health 1996, 8:467-88.

4. Laaksonen M, Prattala R, Lahelma E: Sociodemographic determinants of multiple unhealthy behaviours. Scandinavian Journal of Public Health 2003, I:37-43.

5. Millar WJ, Stephens T: Social status and health risks in Canadian adults: I985 and I99 I. Health Reports 2003, 5:|43-56.

6. Paavola M, Vartiainen E, Haukkala A: Smoking from adolescence to adulthood: The effects of parental and own socioeconomic status. European Journal of Public Health 2004, I 4:4 I 7-2I.

7. Sorensen G, Barbeau E, Hunt MK, Emmons K: Reducing social disparities in tobacco use: a social-contextual model for reducing tobacco use among blue-collar workers. American Journal of Public Health 2004, 94:230-9.

8. American Medical Association website [http://www.amaassn.org]. accessed August 14, 2006

9. Canadian Medical Association website [http://www.cma.ca]. accessed August 14, 2006

10. Canadian Task Force on Preventive Health Care website [http://www.ctfphc.org]. accessed August I4, 2006

II. Katz SL, Hofer TP: Socioeconomic disparities in preventive care persist despite universal coverage. Breast and cervical cancer screening in Ontario and the United States. Journal of the American Medical Association 1994, 272:530-4.

12. Mercer SL, Goel V: Factors associated with the use of mammography: the Ontario Health Survey. Cancer Prevention \& Control 1997, I: |44-5I.

13. Potvin L, Camirand J, Beland J: Patterns of health services utilization and mammography use among women aged 50 to 59 years in the Quebec Medicare system. Medical Care 1995, 33:515-30.

14. Sambamoorthi U, McAlpine DD: Racial, ethnic, socioeconomic, and access disparities in the use of preventive services among women. Preventive Medicine 2003, 37:475-84.

15. Schootman M, Jeffe DB, Reschke AH, Aft RL: Disparities related to socioeconomic status and access to medical care remain in the United States among women who never had a mammogram. Cancer Causes Control 2003, I 4:419-25.

16. National Population Health Survey 1998-9 (Health File, General File, User Guide, Questionnaire, HTML Codebook,
Data Quality Guidelines) [http://library.queensu.ca/webdoc/ ssdc]. accessed August 14, 2006

17. Ostbye T, Yancy WS Jr, Krause KM: Associations between obesity and receipt of screening mammography, Papanicolaou tests, and influenza vaccination: results from the Health and Retirement Study and the Asset and Health Dynamics Among the Oldest Old Study. American Journal of Public Health 2005, 95(9): 1623-30.

18. Love RR, Davis JE, Mundt M, Clark C: Health promotion and screening services reported by older adult patients of urban primary care physicians. Journal of Family Practice 1997, 45(2): | 42-50.

19. Viera AJ, Thorpe JM, Garrett JM: Effects of sex, age, and visits on receipt of preventive healthcare services: a secondary analysis of national data. BMC Health Services Research 2006, 6: 15.

20. Lai DW, Kalyniak S: Use of annual physical examinations by aging Chinese Canadians. Journal of Aging \& Health 2005, I 7(5):573-9I.

21. Harris R, Leininger L: Preventive care in rural primary care practice. Cancer 1993, 72(3 Suppl): I I |3-8.

22. Tudiver F, Fuller-Thomson E: Who has screening mammography? Results from the 1994-1995 National Population Health Survey. Canadian Family Physician 1999, 45:1901-7.

23. Snider J, Beauvais J, Levy I, Villeneuve P, Pennock J: Trends in mammography and Pap smear utilization in Canada. Chronic Diseases in Canada 1996, I7(3-4): 108-17.

24. Tyrell L, Dauphinee D: Task Force on Physician Supply in Canada. Ottawa, Ontario: Canadian Medical Forum Task Force. November 22, 1999

\section{Pre-publication history}

The pre-publication history for this paper can be accessed here:

\section{http://www.biomedcentral.com/1471-2458/6/275/pre} pub

Publish with Biomed Central and every scientist can read your work free of charge

"BioMed Central will be the most significant development for disseminating the results of biomedical research in our lifetime. "

Sir Paul Nurse, Cancer Research UK

Your research papers will be:

- available free of charge to the entire biomedical community

- peer reviewed and published immediately upon acceptance

- cited in PubMed and archived on PubMed Central

- yours - you keep the copyright

Submit your manuscript here:

http://www.biomedcentral.com/info/publishing_adv.asp
BiolMedcentral 